SILVA, Maria Celina Soares de Mello e; TRANCOSO, Márcia Cristina Duarte.

Produção documental de cientistas e a história da ciência: estudo tipológico em arquivos pessoais. História, Ciências, Saúde - Manguinhos, Rio de Janeiro, v.22, n.3, jul.-set. 2015, p.849-861.

\title{
Produção documental de cientistas e a história da ciência: estudo tipológico em arquivos pessoais
}

\author{
Information production by \\ scientists and the history of \\ science: typological study \\ of personal archives
}

\author{
Maria Celina Soares de Mello e Silva \\ Arquivista; coordenadora, curso de mestrado profissional em \\ Preservação de Acervos de C\&T/Museu de Astronomia e Ciências Afins. \\ Rua General Bruce, 586 \\ 20921-030 - Rio de Janeiro - RJ - Brasil \\ celina@mast.br
}

\section{Márcia Cristina Duarte Trancoso \\ Arquivista. \\ Rua General Bruce, 586 \\ 20921-030 - Rio de Janeiro - RJ - Brasil \\ marciacristinatrancoso@gmail.com}

Recebido para publicação em abril de 2013.

Aprovado para publicação em dezembro de 2013.

\section{Resumo}

Aborda o estudo da tipologia documental em arquivos pessoais de cientistas e sua importância para a pesquisa em história da ciência e para o trabalho do arquivista. Apresenta um breve histórico da diplomática à tipologia documental, enfatizando a identificação da atividade produtora do documento como fundamental para sua nomeação. Evidencia as características dos arquivos pessoais no que se refere à diversidade de tipos documentais e, em especial, os de físicos. Além disso, apresenta cinco exemplos de tipos documentais presentes em arquivos de físicos como exemplos da pesquisa em andamento e destaca a elaboração do glossário de espécies e tipos documentais presentes nos arquivos pessoais do Museu de Astronomia e Ciências Afins.

Palavras-chave: arquivos pessoais; tipologia documental; história da ciência.

Abstract

This article addresses the study of document typology in the personal archives of scientists and its importance in the history of science studies and for the archivist's work. A brief history is presented of diplomatic to typological information, emphasizing that identifying document production activity as essential for its classification. The article illustrates personal archive characteristics as regards the diversity of documental types and, in particular, those belonging to physicists. Furthermore, it presents five examples of documental types found in the archives of physicists as examples of research in progress. It also highlights the elaboration of a glossary of different documental kinds and types found in the private archives of Museum of Astronomy and Related Sciences in Rio de Janeiro.

Keywords: personal archives; document typography; history of science. 
A preservação de arquivos pessoais já é prática muito valorizada no Brasil e tem sido incentivada, implementada e utilizada por pesquisadores de diversas áreas do conhecimento. Pesquisadores da história da ciência buscam informações sobre fatos para complementar as fontes oficiais, aquelas presentes nos arquivos institucionais e que, eventualmente, podem fornecer um conhecimento mais voltado para a personalidade, a vida cotidiana e familiar de uma pessoa pública ou proeminente em seu campo de atuação.

O historiador da ciência procura dados para subsidiar suas pesquisas em arquivos, bibliotecas, museus e centros de documentação, além de valer-se do auxílio da história oral e de entrevistas como meio de obter as informações das quais precisa para construir sua história. O que ele normalmente encontra nos arquivos e bibliotecas institucionais são os documentos que representam o produto ou resultado final de uma pesquisa científica ou tecnológica. Os produtos preservados nessas instituições são artigos publicados, relatórios técnicos, pareceres, análises, livros, entre muitos outros documentos que merecem ser mapeados e descritos.

Para um historiador da ciência, entretanto, não basta que sejam preservados apenas esses documentos que representam o resultado final da pesquisa científica e tecnológica, mas também os caminhos percorridos até que um projeto tenha sucesso. A história da ciência busca conhecer os apoios e patrocínios recebidos, a estrutura institucional que propiciou as pesquisas, os profissionais envolvidos e as dificuldades enfrentadas para seu desenvolvimento. Relevantes também são o estudo da história institucional e o papel dos funcionários e das equipes para a realização das atividades institucionais (Silva, 2007, p.25).

Outra abordagem em que a história da ciência tem investido é o estudo das práticas e dos procedimentos científicos, para entender de que modo os números, as tabelas, as máquinas e os gráficos são produzidos, com o objetivo de conhecer onde, como, por quem e por que eles são imaginados e fabricados. Essas informações geralmente estão registradas nos documentos originados das atividades rotineiras de um processo de pesquisa científica ou tecnológica, documentos que, entretanto, não costumam ser encaminhados para os arquivos institucionais. Em geral, eles ficam sob a guarda dos próprios pesquisadores e, como consequência disso, têm destino duvidoso. Sua preservação é incerta porque muitos cientistas consideram que, guardando a separata, o artigo ou qualquer outro produto final de sua pesquisa, as informações sobre a pesquisa estão preservadas. O destino dos documentos das etapas intermediárias da pesquisa, quando não é o descarte aleatório ou o abandono, pode ser os arquivos pessoais dos cientistas, o que os torna fontes valiosas para o pesquisador da ciência (Silva, 2007, p.26-27).

\section{Os arquivos pessoais de cientistas}

O historiador da ciência se utiliza dos arquivos pessoais como fonte para buscar documentos que normalmente não são recolhidos aos arquivos das instituições em que o pesquisador atuou. São documentos que muito provavelmente cientistas guardaram em suas residências como testemunho das atividades exercidas ao longo de uma vida, seja como comprovante de um êxito concreto, seja como recordação de algum feito que lhe foi muito caro - geralmente são guardados por razões sentimentais.

Os arquivos pessoais de cientistas, artistas e políticos constituem matéria privilegiada para que se possam compreender os processos de conhecimento, criação e decisão, razão 
por que, aliás, têm sido objeto de iniciativas de recolhimento por instituições diversas (Camargo, Goulart, 2007, p.50).

A importância dos arquivos pessoais como fonte de informações fundamentais para a recuperação da memória ou para o desenvolvimento da pesquisa histórica, científica ou tecnológica do país foi reconhecida por lei. Alguns arquivos pessoais podem ser classificados como "de interesse público e social" no Brasil quando, então, a lei determina que sejam preservados e colocados à disposição dos pesquisadores. Por se tratar de documentos de natureza privada, os arquivos pessoais reúnem, muitas vezes, informações cujo acesso pode comprometer a intimidade de seu titular ou de terceiros. Por isso, esses documentos passaram a ser alvo da legislação. O Conselho Nacional de Arquivos (Conarq) - órgão colegiado vinculado ao Arquivo Nacional do Ministério da Justiça, cuja finalidade é definir normas e diretrizes de política nacional para os arquivos - foi criado pela lei 8.159, de 1991, conhecida como Lei de Arquivos. O Conarq publicou a resolução 12, revogada pela resolução 17, de 25 de julho de 2003, que dispõe sobre os procedimentos relativos à declaração de interesse público e social de arquivos privados de pessoas físicas ou jurídicas que contenham documentos relevantes para a história, a cultura e o desenvolvimento nacional. Além dessa resolução, o decreto 4.073, que regulamenta a lei 8.159, dispõe sobre a Política Nacional de Arquivos Públicos e Privados e dá outras providências. O artigo 5 do decreto determina que:

Os arquivos privados de pessoas físicas ou jurídicas que contenham documentos relevantes para a história, a cultura e o desenvolvimento nacional podem ser declarados de interesse público e social.

Parágrafo único - A declaração de interesse público e social de que trata este artigo não implica a transferência do respectivo acervo para a guarda em instituição arquivística pública, nem exclui a responsabilidade por parte de seus detentores pela guarda e a preservação do acervo (Brasil, 3 jan. 2002).

Com a legislação federal, o Estado reconhece e promove a preservação de arquivos pessoais de valor histórico como de interesse público, consolidando, assim, ações de identificação e recolhimento desses documentos a instituições de custódia, como arquivos, bibliotecas e museus.

Arquivos pessoais de cientistas têm sido preservados nessas instituições, a exemplo do Centro de Pesquisa e Documentação de História Contemporânea do Brasil/Fundação Getulio Vargas, do Museu de Astronomia e Ciências Afins/Ministério da Ciência, Tecnologia e Informação, da Casa de Oswaldo Cruz/Fiocruz e de universidades.

Uma das características dos arquivos pessoais de cientistas e pesquisadores em geral é que normalmente apresentam muito mais documentos produzidos por sua atividade científica, ou seja, fruto de seu trabalho, que os produzidos pelas atividades relacionadas à sua vida privada doméstica, em família, ou entre amigos. Também são poucos os que fornecem registros sobre atividades ligadas ao lazer, como esportes, artes etc., ou sobre sua crença religiosa.

Esses arquivos apresentam ampla variedade de documentos produzidos por diversas atividades no decorrer de uma vida, e que possuem características diferenciadas. O estudo dos tipos de documentos, ou tipologia documental, permite o reconhecimento dos documentos e de suas características físicas, relacionando-os às atividades que lhes deram origem, e a análise 
dos elementos que não estão presentes nos documentos, quando então são identificadas as funções ou atividades que os geraram. A pesquisa da tipologia documental em arquivos tem sido cada vez mais utilizada pela arquivologia, pois se tem demonstrado de grande utilidade nas atividades arquivísticas de identificação, classificação e descrição.

\section{Tipologia documental}

A tipologia documental vem sendo utilizada pela arquivologia como consequência dos métodos da diplomática surgida no século XVII para crítica e análise da autenticidade dos documentos da Igreja. Monges beneditinos, que possuíam tradição de estudos e de reprodução de fontes documentais, receberam críticas dos jesuítas quanto à autenticidade de documentos sobre a vida dos santos. Jean Mabillon, que pertencia à abadia de Saint-Denis, publicou, em 1681, a obra diplomática chamada De re diplomatica libri VI, com o objetivo de justificar a eficiência dos documentalistas beneditinos. Nela, o autor definiu regras de crítica textual, avaliando a forma do documento, o conjunto de caracteres extrínsecos (papel, escrita) e intrínsecos (língua, texto) dos quais se constituem (Bellotto, 2008, p.2-3).

O estudo da diplomática levou à análise e à verificação da autenticidade dos documentos, de forma criteriosa, e conduziu ao atual estudo dos tipos documentais pela arquivologia. A diplomática pode ser considerada o núcleo duro que deu origem à ciência arquivística (Leal, Siqueira, 2011). Hoje a arquivologia se utiliza da diplomática para realizar uma análise dos tipos documentais, chamada de análise tipológica, que tem por objetivo analisar o documento de arquivo em sua constituição, considerando o suporte, o conteúdo e a estrutura.

A abordagem tipológica estuda as características que a informação apresenta nos documentos e como estão configuradas. Para Bellotto (2002, p.19; destaques no original):

Enquanto a espécie documental é o objeto da diplomática, a tipologia documental, representando melhor uma extensão da diplomática em direção à arquivística, tem por objeto o tipo documental, entendido como a 'configuração que assume a espécie documental de acordo com a atividade que a gerou'.

A análise tipológica do documento reconhece as características intrínsecas e extrínsecas dos documentos, com o objetivo de identificar a atividade que lhe deu origem, buscando nomeá-los corretamente. E isso é fundamental. Para Heredia Herrera (2007, p.46), “Os nomes das coisas são o primeiro passo para seu reconhecimento". ${ }^{1}$

O estudo das tipologias documentais pela arquivística é importante para as atividades de identificação, classificação e descrição de documentos. Além do trabalho do arquivista, o conhecimento dos tipos de documentos também auxilia em muito a pesquisa por parte dos usuários. É o que enfatiza Oliveira (2012, p.83-84):

O estudo do tipo documental permite analisar aspectos não explicitados na estrutura do documento, fornecendo elementos para compreender o comportamento da sociedade, ou de seus segmentos em determinadas situações, como o casamento, o nascimento, a morte, a primeira comunhão, os banquetes, as comunicações do cotidiano. A identificação dos tipos documentais adequada, demonstrando seu vínculo com a atividade ou ato que dá origem à criação do documento, oferece aos usuários amplas possibilidades de abordagem dos arquivos, seja para a história social, a psicologia ou a cultura. 
Os estudos de tipologia documental estão se tornando fundamentais na arquivologia hoje, e muitas iniciativas têm sido publicadas em artigos e glossários específicos de determinadas áreas do conhecimento.

\section{Tipologia documental em arquivos de cientistas}

Estudar os tipos documentais em arquivos pessoais de cientistas é tarefa com grande potencial de estudo. A produção documental científica é ampla, e a variedade de tipos é um universo ainda a ser explorado. Levando-se em consideração que há liberdade para a seleção dos documentos a preservar como arquivo pessoal, que todos nós temos, uma variedade de tipos documentais pode ser encontrada nos arquivos pessoais de cientistas. A criatividade para a produção documental também deve ser levada em consideração. Em muitos casos, os documentos são desconhecidos e precisam ser identificados e nomeados.

Nos arquivos pessoais de cientistas, grande parte dos documentos é fruto de suas atividades profissionais, e muitos só são encontrados nesses arquivos. São documentos produzidos de forma preliminar, como rascunho, minuta ou anotações iniciais de um projeto, antes da versão final. Esses documentos, quando não são descartados, podem ir parar nos arquivos pessoais e acabam servindo de testemunho de fases importantes de uma pesquisa. Para decifrar esse universo, fazem-se necessárias análise e identificação criteriosas. A análise documental visa não apenas ao conhecimento do documento, mas também à definição da forma correta de nomeá-lo.

O Arquivo de História da Ciência do Museu de Astronomia e Ciências Afins está pesquisando a tipologia documental em arquivos de ciência e tecnologia e, em especial, em arquivos pessoais de cientistas. A pesquisa objetiva elaborar um glossário para padronização dos termos, com a definição de cada tipo documental. Esse é, também, um dos objetivos da análise tipológica, identificando as denominações para os documentos e adequando-as à época em que foram produzidas. Uma dificuldade é a variedade de registros e formas de expressão entre as pessoas. Heredia Herrera (2007) esclarece que os tipos documentais não são estáveis em seus números, podem desaparecer e evoluir frente às transformações sociais e tecnológicas, contudo não podemos perder de vista os primeiros nomes reconhecidos.

O glossário produzido como consequência da padronização dos termos será utilizado para o próprio trabalho de identificação, classificação e descrição de arquivos pessoais de cientistas. E, como tal, deverá ser atualizado a cada novo arquivo organizado. A pesquisa visa conhecer os documentos, identificando as atividades que lhes deram origem, o que contribui para a correta ordenação dentro de um quadro de classificação.

Para este artigo, foram selecionados alguns exemplos de tipos documentais presentes em arquivos pessoais de físicos e o estudo que está sendo realizado.

A atividade de um físico pode ocorrer em laboratórios específicos, em salas de trabalho com a utilização de computadores ou ainda em campo, dependendo da especialidade da área de atuação. Invariavelmente, cientistas trocam correspondência com seus pares sobre o trabalho e a pesquisa que estão realizando. São cartas do tempo em que não havia computadores portáteis nas residências ou nas salas de trabalho com a facilidade de hoje, quando os e-mails ainda não reinavam como correspondência principal de qualquer atividade, profissional ou 
pessoal. As cartas eram manuscritas ou datilografadas, com cópias em papel carbono que permaneciam em poder do remetente. A troca de informações sobre a pesquisa, por meio de carta, era muito comum. O conteúdo inicia como padrão, com as devidas saudações, e após tem início o objetivo da carta, seguido dos dados técnicos que se quer intercambiar. Também podem ter informações sobre o envio, em anexo, de separatas, relatórios, pareceres e cálculos diversos. Como tipificar uma carta como essa? Simplesmente como "carta de envio", "carta de solicitação de informação", ou "carta de envio de informação"? Cartas com essas características de intercâmbio diverso de informações sobre dados da pesquisa foram tipificadas como "carta de intercâmbio de informação científica". Na definição é explicitado que esse tipo de carta pode conter outros tipos documentais embutidos, como os já citados, mas que, em sua essência, trata-se de trocas de informação científica. É preciso deixar o assunto preponderante prevalecer no tipo documental. Essa solução é abrangente e dá conta de tipificar documentos dos vários fundos do acervo, independente da área do conhecimento do cientista. A Figura 1 apresenta um exemplo de carta de informação científica.

A carta da Figura 1 foi endereçada a Bernhard Gross no período em que trabalhava na Comissão Nacional de Energia Nuclear com pesquisas na área de eletricidade, especificamente com eletretos. O remetente respondia a uma pergunta de Gross sobre dados da pesquisa, embora a carta comece com um agradecimento.

Outro tipo documental também muito presente em arquivos pessoais de cientistas da era pré-informática são os cadernos de anotações. O caderno não é espécie ou tipo, é o formato do documento. Mas, como é mais conhecido por sua forma, é um dos exemplos de formato elevado à categoria de espécie. Cadernos de anotações são muito utilizados por cientistas que não querem perder seus rascunhos registrados em folhas avulsas, preferindo guardar em cadernos, que podem ser acessados facilmente e a qualquer momento. Esses cadernos possuem os mais variados apontamentos, como o desenvolvimento da pesquisa, comentários sobre outros trabalhos, cálculos e gráficos, opiniões sobre artigos e textos diversos, entre outras possibilidades. Pode haver títulos, quando se trata de um rascunho de artigo, de matéria a ser lecionada, ou de anotações sobre uma leitura realizada. O exemplo da Figura 2 é um caderno de anotações de Elisa Frota Pessoa sobre o plano de estudo de determinado mineral, datado de 22 de junho de 1942, período em que era estudante de física na Faculdade Nacional de Filosofia da Universidade do Brasil. Os cadernos têm as informações configuradas livremente.

Quando o cientista também é professor, desempenhando dupla função, ele produz o que hoje chamamos de "apostila". Esse tipo documental varia de nome no tempo e no espaço, podendo ainda ser denominado "notas de aula"; porém o termo "apostila" é hoje o mais utilizado. As notas de aula são usadas pelos professores e contêm os temas do conteúdo a ser transmitido em classe. Em relação aos alunos, o termo mais utilizado seria "anotações de aula", documento em que são registradas as informações recebidas em sala. Na Figura 3, temos um exemplo de "notas de aula", em que se vê a capa do documento.

A "Nota de aula" da Figura 3 foi preparada por Bernhard Gross para o curso de pósgraduação ministrado no Laboratório de Eletretos do Instituto de Física e Química de São Carlos, da Universidade de São Paulo. Na capa do documento constam o título, "Efeitos elétricos e irradiação de dielétricos por radiação ionizante", e informações sobre o curso 
Dr. Bernhard Gross

Comssas Naional de Frerge Tudear

Rir de Jameiro, GB, Brasil

\section{En 7 de Marco de 1968}

\section{Prezado Dr. Gross:}

Esta é em resposta a cartas datadas de $22 / 2$ e 26/1 deste. Fur primeiro hugar agradeco a gentileza de ter falado sobe mim no I.Pq. da Mariuha. Se realguente for ao Brazil reste verão uas rérei dívidas em ir falar com o Comandante Azevedo. Qunauts as "paper" sêbre eletretos ño acho que entendi claramente suas pergontas sthe 0 masmo. De unaneira que vou apenas fazer alguns "statements", Md esperanca que eles on respondam suas perguntas on moTivem novas perguntas que entān sejemn enais claras. As diculdades advem, óbriamento, do As dificuldades adven, obriamento, da
syygy, minhd ignorancia da Fisica enval-
vida!! vida! 
e a universidade. Vale destaque para o crédito à pessoa que datilografou o documento, provavelmente a própria secretária do curso.

Cientistas também se utilizam de folhas avulsas para fazer anotações diversas referentes ao trabalho científico, e não apenas de cadernos. As anotações podem receber denominações diversas por parte deles, pois não estão minimamente preocupados com padronização ou com

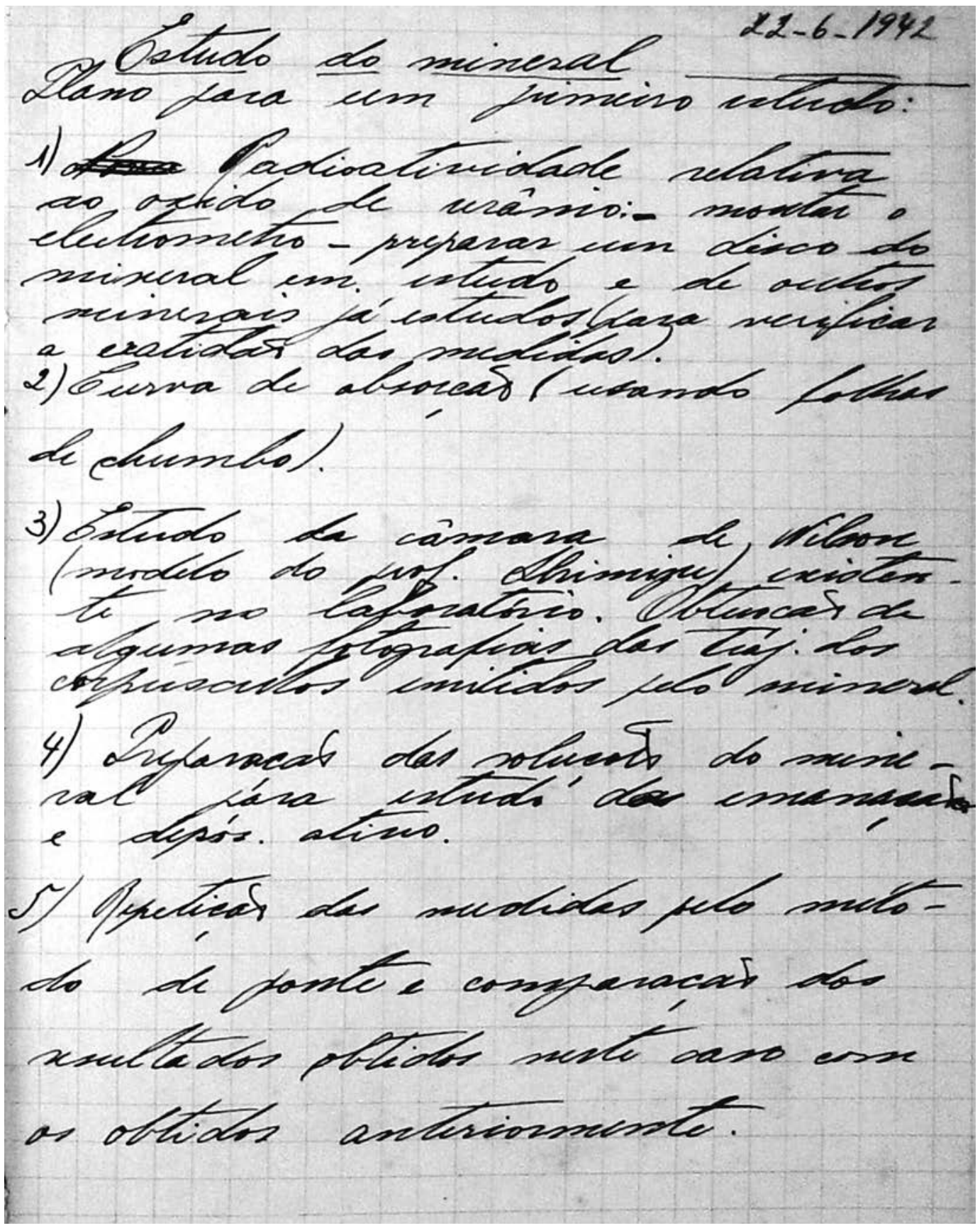

Figura 2: Caderno de anotações (Fonte: Arquivo Elisa Frota Pessoa/Acervo Mast) 


\section{BG.T.2.1.CO3}

\section{EFEITOS ELETRICOS DE IRRADIACCAO DE DIELETRICOS}

\section{POR RADIAÇOES IONIZANTES}

Bernhard Gross

Notas de Aulas do Curso de Pós-Gradua ção ministrado em 1983 com Auxílio do CNPq e da FAPESP no Laboratório de Eletretos.

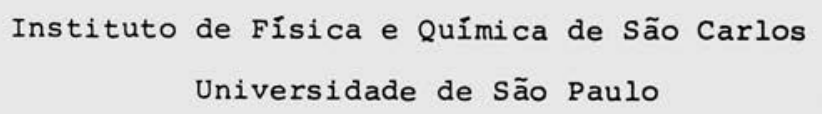

Trabalho datilográfico: Yvone Biason

São Carlos 1983 
a correta denominação dos documentos. A liberdade de expressar suas ações acaba dando origem a documentos com denominações que precisam ser mapeadas e estudadas pelos arquivistas. Um exemplo é o da Figura 4, que apresenta um manuscrito chamado "crítica" pelo cientista. Foi elaborado a tinta pelo próprio, com caligrafia de fácil compreensão. Esse documento tanto pode ser uma peça isolada como pode fazer parte de um contexto do qual tenha sido desmembrado. O tipo documental "crítica", conforme batizado pelo cientista, é um "parecer" ou análise crítica de trabalho enviado para sua avaliação. O termo "crítica", que se refere ao produto da ação de criticar, não seria o termo mais correto para nomear o tipo documental. A opção está em chamá-lo de "parecer" e acrescentar no glossário a informação: "substitui crítica".

A minuta de parecer da Figura 4 refere-se à atuação de Bernhard Gross na Academia Brasileira de Ciências, onde manifestava sua opinião sobre vários assuntos. No caso, trata-se de uma minuta de parecer sobre efeito termodielétrico.

O último exemplo a ser abordado é o poema, tipo documental fácil de ser reconhecido. O poema faz parte do gênero literário poesia e pode ser encontrado em arquivos pessoais, mas não muito comumente em arquivos de cientistas. Em uma primeira avaliação, temos a tendência de considerar que é fruto de uma atividade pessoal, como a de escrever poesias em momentos de lazer, ou de copiar poemas de seu agrado pessoal, para colecioná-los e recordá-los.

A Figura 5 apresenta um poema sem identificação de autoria e sem data, não apresentando referências contextuais. Analisando o conteúdo, verifica-se que se trata de um poema que fala da profissão de físico e de sua vocação. É praticamente uma homenagem ao físico. Conhecendo bem a biografia do produtor do arquivo, em que não há qualquer indicação de que ele escrevesse poesias ou de que gostasse particularmente desse gênero literário, e verificando que a caligrafia não é a de Gross, é bem provável que tenha sido uma homenagem a ele ou um presente. Tanto pode ter sido por parte de alunos como de colegas de trabalho ou profissão ou qualquer outro tipo de homenagem, que só um trabalho de pesquisa mais apurado poderá determinar. Esse exemplo consolida a importância de conhecer a biografia do produtor dos documentos para uma classificação mais consistente e fundamentada. Fato é que essas informações contribuem para a classificação dos documentos em um quadro de arranjo. Nesse caso, o conhecimento da biografia, aliado à classificação por atividade, resultou na opção por vincular o poema a documentos de trabalho, e não aos documentos oriundos de atividades de cunho pessoal.

Muitos outros tipos documentais estão sendo identificados e mapeados, mas os cinco documentos apresentados já fornecem uma amostra do trabalho que está sendo realizado e do potencial informativo que um documento é capaz de oferecer para arquivistas e pesquisadores.

\section{Considerações finais}

O estudo de tipologia documental, além de ser tarefa estimulante, é muito útil para o trabalho de arquivistas e de pesquisadores da história da ciência. Para arquivistas, o conhecimento dos documentos auxilia a identificação por semelhança, reconhecendo os que apresentam características similares. Também é útil para a descrição de um item ou de um conjunto de documentos, pois uma descrição bem estruturada, incluindo os tipos 


\section{Citivas}

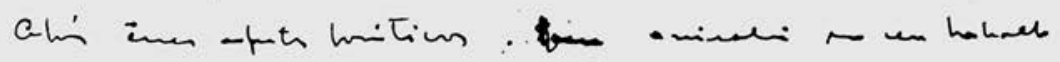

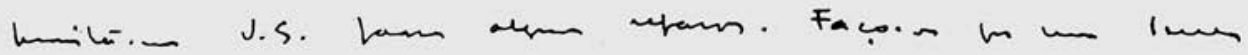

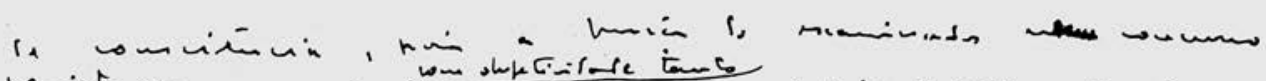

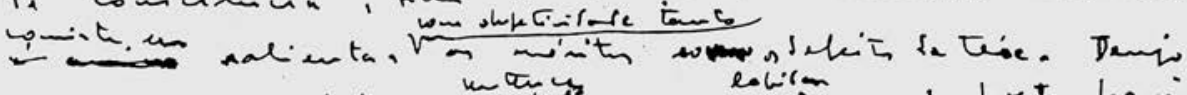

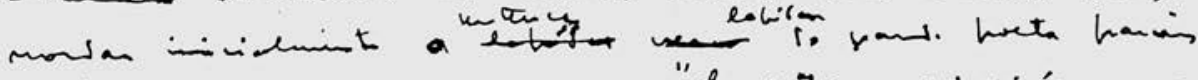

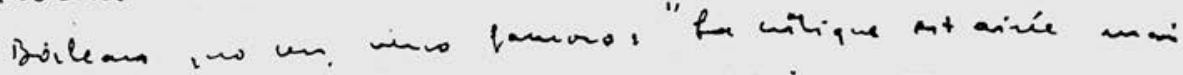

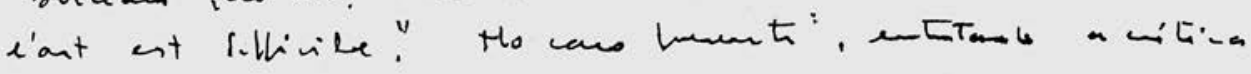

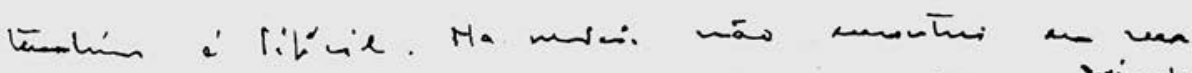

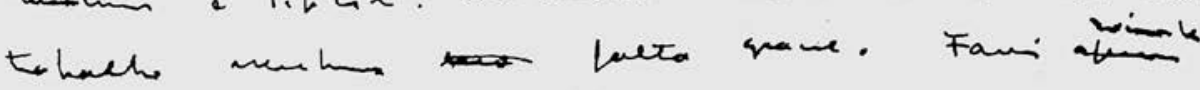

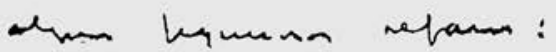

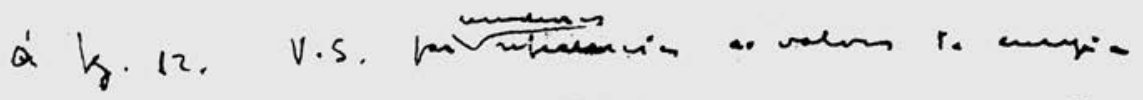

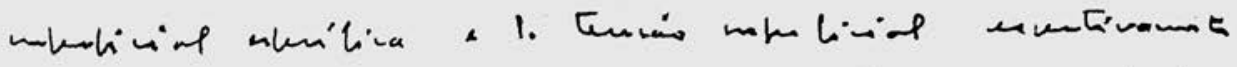

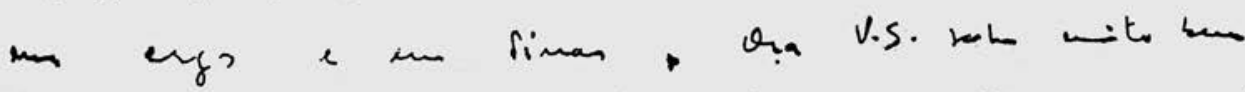

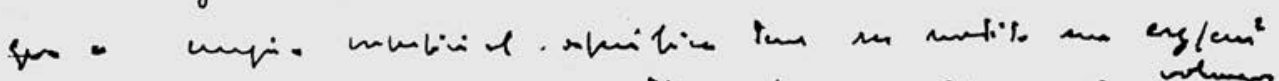

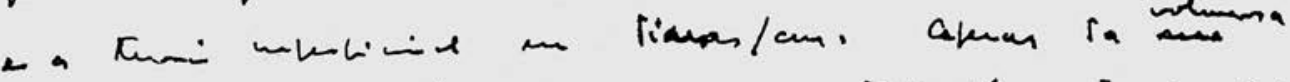

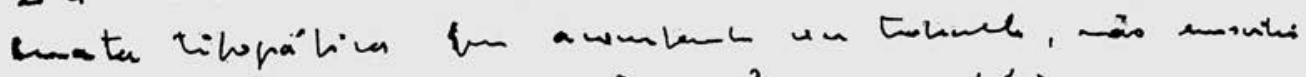

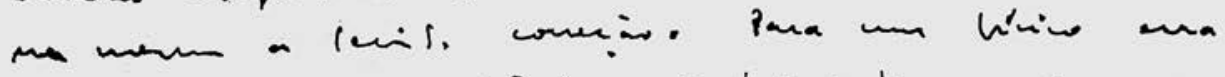

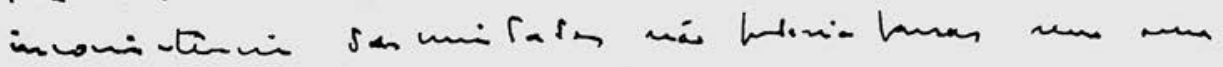

\section{anio.}

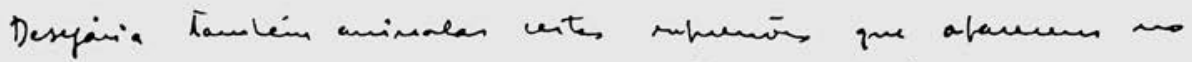

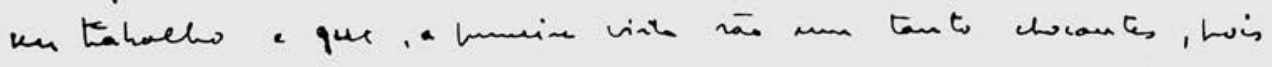

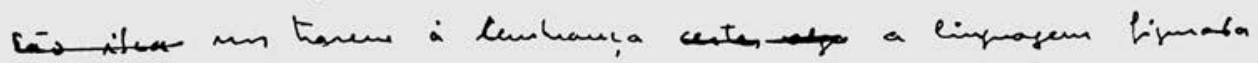

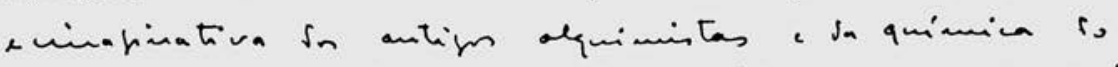

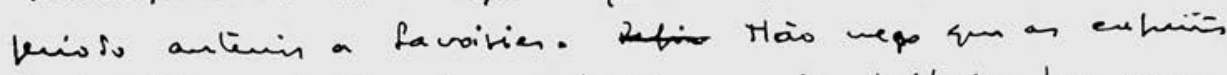

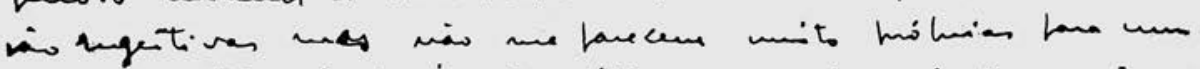

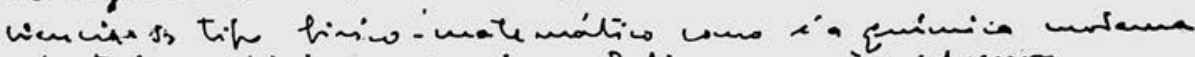

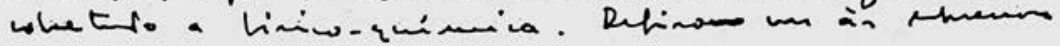


$F_{1 g} \cdot 28$

BG.T.2.J.0C3

There once was an electron gun.

It was mounted at Bell,

one day it worked well

and gave people much pleasure and fun.

It produced electrons and holes

and homo- and hetero-poles.

But electrons and holes disappeared!

This a physicist thought to be weird.

Like a dentist wielding his tool he extracted the holes from the pool. But the holes ran away in great haste, it was a terrible waste.

The physicist, awfully bright, concluded This couldn't be right. He caught the holes in a box and proved it was all just a hoax. 
documentais, permite melhor compreensão do contexto de produção dos documentos. Além disso, o estudo tipológico analisa o documento levando em consideração a atividade que o gerou, o que fornece mais informações de contexto. Uma descrição contextualizada só enriquece os instrumentos de pesquisa produzidos.

Já os pesquisadores de história da ciência, quando se deparam com um instrumento de busca bem elaborado, com informações sobre o contexto de produção dos documentos, percebem o quanto de trabalho poupado o instrumento lhe permitiu. A descrição documental fica engrandecida com a identificação e a correta nomeação dos documentos. Para tal, é fundamental a elaboração de um glossário com a definição dos termos, que pode ser consultado tanto por arquivistas - para a própria atividade de identificação, descrição e classificação como por pesquisadores, que terão a facilidade de reconhecer e compreender o que representa cada tipo documental.

A pesquisa está em andamento e tem como objetivo mapear as atividades desempenhadas por um cientista e identificar os tipos documentais produzidos em cada uma delas. Além disso, visa elaborar um glossário amplo para utilização de arquivistas e pesquisadores, que será constantemente atualizado com as informações de cada novo arquivo organizado.

\section{NOTA}

${ }^{1}$ Nessa e nas demais citações de textos em outros idiomas, a tradução é livre.

\section{REFERÊNCIAS}

BELLOTTO, Heloísa Liberalli.

Diplomática e tipologia documental em arquivos. Brasília: Briquet de Lemos. 2008.

BELLOTTO, Heloísa Liberalli.

Como fazer análise diplomática e análise tipológica de documento de arquivo. São Paulo: Associação de Arquivistas de São Paulo/Arquivo do Estado. (Projeto Como Fazer, 8). 2002.

BRASIL.

Decreto n.4.073, de 3 de janeiro de 2002. Regulamenta a Lei n.8.159, de 8 de janeiro de 1991, que dispõe sobre a política nacional de arquivos públicos e privados. Disponível em: http://www.planalto.gov.br/ccivil_03/ decreto/2002/d4073.htm. Acesso em: 10 nov. 2010. 3 jan. 2002.

CAMARGO, Ana Maria de Almeida; GOULART, Silvana.

Tempo e circunstância: a abordagem contextual dos arquivos pessoais - procedimentos metodológicos adotados na organização dos documentos de Fernando Henrique Cardoso. São Paulo: Instituto Fernando Henrique Cardoso. 2007.

HEREDIA HERRERA, Antonia.

En torno al tipo documental. Arquivo \& Administração, v.6, n.2, p.25-50. 2007.

LEAL, João Eurípedes Franklin; SIQUEIRA, Marcelo Nogueira de.

Glossário de paleografia e diplomática. Rio de Janeiro: Multifoco. 2011.

OLIVEIRA, Lucia Maria Velloso de.

Descrição e pesquisa: reflexões em torno dos arquivos pessoais. Rio de Janeiro: Móbile. 2012.

SILVA, Maria Celina Soares de Mello e.

Visitando laboratórios: o cientista e a preservação de documentos. Tese (Doutorado em História Social) - Universidade de São Paulo, São Paulo. 2007.

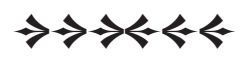

